\title{
REKAYASA DAN MANUFAKTUR KOMPOSIT SANDWICH HIBRID UNTUK PANEL
}

\author{
Agus Hariyanto \\ Teknik Mesin Universitas Muhammadiyah Surakarta \\ J1. A.Yani Tromol Pos I Pabelan, Kartosura \\ Email: agus.hariyanto@ums.ac.id
}

\begin{abstract}
ABSTRAK
Tujuan penelitian ini adalah menyelidiki pengaruh fraksi volume core terhadap peningkatan kekuatan Impak komposit sandwich hibrid berpenguat kombinasi serat rami woven dan serat gelas woven bermatrix polyester dengan core berpenguat kombinasi serbuk kayu jati dan mahoni bermatrix polyester. Mekanisme perpatahan diamati dengan foto makro.

Bahan yang digunakan untuk skin adalah serat rami (woven), serat E-Glass (woven), resin unsaturated polyester 157 BQTN (UPRs). Bahan yang digunakan untuk core adalah serbuk kayu jati dan mahoni dengan mesh 30 pada fraksi volume 30\%, 40\%, dan 50\%, resin unsaturated polyester 157 BQTN. Hardener yang digunakan adalah MEKPO dengan konsentrasi 1\%. Komposit dibuat dengan metode cetak tekan. Komposit sandwich hibrid tersusun terdiri dari dua skin komposit hibrid dengan core hibrid ditengahnya. Skin komposit hibrid sebagai lamina terdiri dari dua lamina serat gelas anyam dan satu lamina serat rami (woven - woven-woven). Fraksi volume serat komposit skin hibrid adalah 30\%. Komposit core hibrid yang digunakan adalah serbuk kayu jati dan mahoni dengan mesh 30 pada fraksi volume $30 \%$, 40\%, dan 50\% dengan resin unsaturated polyester 157 BQTN. Variabel utama penelitian yaitu fraksi volume core (30\%, 40\%, dan 50\%). Spesimen dan prosedur pengujian Impak mengacu pada standard ASTM D 5942.

Hasil penelitian menunjukkan bahwa penambahan fraksi volume core mampu meningkatkan energi serap dan kekuatan impak komposit sandwich hibrid. Mekanisme patahan diawali oleh kegagalan komposit skin bagian tarik, core gagal geser, dan diakhiri oleh kegagalan skin sisi tekan. Pada bagian daerah batas core dan komposit skin menunjukkan adanya kegagalan delaminasi.
\end{abstract}

Kata Kunci: komposit sandwich hibrid, kekuatan impak, fraksi volume, mekanisme patahan.

\begin{abstract}
The objective of this research is to investigate the effect of core's volume fraction to the increment of impact strengthness of sandwich hybrid composite reinforced with the combination of ramie fiber and polyester matrixed woven glass fiber with the core reinforced with the combination of teakwood powder and polyester matrixed mahony. The fracture mechanism is observed with macro photo.

Materials that are utilized for skin are ramie fiber (woven), fiber E-Glass (woven), and 157 BQTN unsaturated polyester resin (UPRs). Materials that are utilized for core are teakwood and mahony powder with 30 meshes on $30 \%, 40 \%$, and $50 \%$ volume fraction
\end{abstract}


of 157 BQTN unsaturated polyester resin. Hardener which is utilized is MEKPO with 1\% concentration. Composite is made by print presses method. Sandwich hybrid composite consists of two skins hybrid composite with hybrid core between them. Hybrid composite skin as lamina consists of two lamina of glass fiber woven and one lamina ramie fiber (woven- woven - woven). Volume fraction of hybrid composite skin is $30 \%$. Hybrid cores composite which are used are teakwood and mahony powder with 30 meshes $30 \%, 40 \%$, and $50 \%$ volume fraction of 157 BQTN unsaturated polyester resin. The main variable of this experiment is the volume fraction of the core $130 \%$, 40\%, and 50\%). Specimen and impact examination procedure reffer on ASTM D 5942 standard.

The results show that the increment of the volume fraction of the core can increase absorb energy and impact strengness of sandwich hybrid composite. The fracture mechanism was started by the failure of the tensile part of composite's skin, followed by shear failure of the core, and ended up by the failure of compression side of the skin. On the boundary region between core and skin pointed out that there was delamination failure.

Keyword: sandwich hybrid composite, impact strength, volume fraction, fracture mechanism.

\section{PENDAHULUAN}

Munculnya issue permasalah limbah non-organik serat sintetis yang semakin bertambah mampu mendorong perubahan trend teknologi komposit menuju natural composite yang ramah lingkungan. Serat alam mencoba menggeser serat sintetis, seperti E-Glass, Kevlar-49, Carbon/Graphite, Silicone carbide, Aluminium Oxide, dan Boron. Salah satu jenis serat alam yang tersedia secara melimpah adalah serat rami. Keuntungan penggunaan komposit antara lain ringan, tahan korosi, tahan air, performance-nya menarik, dan tanpa proses pemesinan. Beban konstruksi juga menjadi lebih ringan. Harga produk komponen yang dibuat dari komposit glass fibre reinforced polyester (GFRP) dapat turun hingga 60\%, dibanding produk logam (Abdullah dan Handiko, 2000). Komposit sandwich hibrid merupakan salah satu jenis komposit struktur yang sangat potensial untuk dikembangkan. Komposit ini terdiri dari flat hibrid komposit dan core hibrid. Core yang biasa dipakai adalah core import, seperti polyuretan (PU), polyvynil Clorida (PVC), dan honeycomb.

Ketersediaan serbuk kayu jati dan mahoni yang berlimpah, merupakan SDA yang dapat direkayasa menjadi produk teknologi andalan nasional sebagai core hibrid komposit sandwich hibrid. Rekayasa core hibrid dapat dilakukan dari kayu utuh ataupun limbah serbuk/potongan kayu. Konsep rekayasa core hibrid ini merupakan tahapan alih teknologi yang diilhami oleh masuknya core impor kayu balsa dari Australia. Sifat fisik serbuk kayu jati dan mahoni hampir sama dengan kayu balsa.

Berdasarkan uraian tersebut, maka penelitian tentang rekayasa komposit sandwich hibrid dengan core hibrid limbah serbuk kayu jati dan mahoni merupakan kajian yang sangat menarik untuk diteliti lebih lanjut. Berhubung mayoritas beban yang diterima berbagai panel komposit sandwich hibrid adalah bending, maka kajian mekanis yang dipandang sangat penting dilakukan adalah kajian kekuatan bending.

\section{TINJAUAN PUSTAKA}

Hariyanto meneliti pengaruh ketebalan core dan perlakuan alkali serat kenaf terhadap peningkatan kekuatan bending komposit hybrid sandwich kombinasi serat kenaf dan serat 
gelas bermatrix Polyester dengan core kayu sengon laut [1]. Bahan yang digunakan adalah serat kenaf (acak, anyam), serat E-Glass (anyam), resin unsaturated polyester 157 BQTN (UPRs), kayu sengon laut, dan $\mathrm{NaOH}$ teknis. Hardener yang digunakan adalah $M E K P O$ dengan konsentrasi $1 \%$. Variabel utama penelitian yaitu perlakuan alkali serat kenaf $(0$ \& 2 jam) dan tebal core $(5,10,15,20 \mathrm{~mm})$. Komposit dibuat dengan metode cetak tekan. Fraksi volume serat komposit adalah 30\%. Pengujian komposit sesuai dengan standar ASTM yang digunakan pengujian bending yang mengacu pada standar ASTM C 393-00. Hasil penelitian menunjukkan bahwa penambahan ketebalan core mampu meningkatkan kekuatan bending dan momen bending komposit hybrid sandwich. Perlakuan alkali pada serat kenaf menurunkan kekuatan bending pada komposit hybrid sandwich. Mekanisme patahan diawali oleh kegagalan komposit skin bagian tarik, core gagal geser, dan diakhiri oleh kegagalan skin sisi tekan. Pada bagian daerah batas core dan komposit skin menunjukkan adanya kegagalan delaminasi.

\section{Sifat Mekanis Komposit Sandwich}

Wahyanto dan Diharjo menyimpulkan bahwa komposit sandwich serat gelas acak 300 $\mathrm{gr} / \mathrm{m}^{2}$ pada $\mathrm{V}_{\mathrm{f}}=30 \%$ bermatrik polyester dengan core kayu sengon laut setebal $10 \mathrm{~mm}$ memiliki kekuatan bending dan impak 125,44 MPa dan 0,045 Mpa [2]. Menurut Febrianto dan Diharjo pada komposit hibrid sandwich serat E-glass acak $300 \mathrm{gr} / \mathrm{m}^{2}$ dan kenaf anyam $810 \mathrm{gr} / \mathrm{m}^{2}$ pada $\mathrm{V}_{\mathrm{f}}=30 \%$ bermatrik polyester dengan core kayu sengon laut setebal $10 \mathrm{~mm}$, kekuatan bending dengan core arah serat kayu horisontal adalah 263,28 MPa, lebih besar $81 \%$ di atas komposit sandwich hibrid dengan core kayu vertikal 97,5 Mpa [3]. Kekuatan impak komposit sandwich dengan core vertikal $0,0604 \mathrm{~J} / \mathrm{mm}^{2}$, lebih besar $4,4 \%$ di atas kekuatan impak dengan core arah serat kayu horisontal $0,0578 \mathrm{~J} / \mathrm{mm}^{2}$.

\section{Aspek Geometri}

Menurut Gibson penempatan serat harus mempertimbangkan geometri serat, arah, distribusi, dan fraksi volume, agar dihasilkan komposit berkekuatan tinggi [4]. Untuk suatu lamina unidirectional, dengan serat kontinu dengan jarak antar serat yang sama, dan direkatkan secara baik oleh matrik, seperti ditunjukkan pada gambar 1. Fraksi volume dapat dihitung dengan menggunakan persamaan [5]:

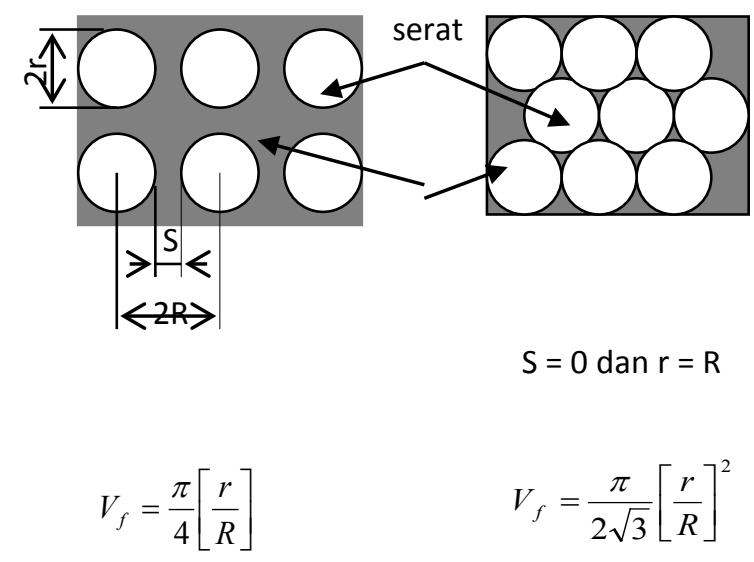

Gambar 1 Struktur mikro komposit dengan peletakan serat teratur [4]. 


$$
\begin{aligned}
& V_{1}=\frac{W_{1} / \rho_{1}}{W_{1} / \rho_{1}+W_{2} / V_{2}+\ldots . .} \\
& W_{1}=\frac{\rho_{1} V_{1}}{\rho_{1} V_{1}+\rho_{2} V_{2}+\ldots \ldots}
\end{aligned}
$$

dengan catatan :

$\mathrm{V}_{1}, \mathrm{~V}_{2}, \ldots=$ fraksi volume, $(\%)$

$\mathrm{W}_{1}, \mathrm{~W}_{2}, \ldots=$ fraksi berat, $(\%)$

$\rho_{1}, \rho_{2}, \ldots=$ densitas bahan pembentuk, $\left(\mathrm{gr} / \mathrm{Cm}^{3}\right)$

Kekuatan komposit dapat ditentukan dengan persamaan [5]:

$$
\sigma_{\mathrm{C}}=\sigma_{\mathrm{f}} \mathrm{V}_{\mathrm{f}}+\sigma_{\mathrm{m}} \mathrm{V}_{\mathrm{m}}
$$

\section{Kekuatan Impak Komposit Sandwich}

Pada umumnya, material komposit mempunyai nilai impak dan energi serap. Akibat pengujian impak, pada bagian sisi kanan spesimen mengalami tekanan, dan bagian sisi kiri mengalami tarikan. Kegagalan yang terjadi akibat uji impak komposit yaitu mengalami patah pada bagian sisi kiri karena tidak mampu menahan tegangan tarik. Kekuatan impak komposit dapat ditentukan dengan persamaan (4) [6]:

$$
a_{c U}=\frac{W}{h \times b} \times 10^{3}=\frac{W}{h \times b}
$$

Energi serap dapat ditentukan dengan persamaan (5) [6]:

$$
\mathrm{W}=\mathrm{GxR}(\cos \beta-\cos \alpha)
$$

\section{Mode Kegagalan Impak Komposit Sandwich}

Hillger mengemukakan bahwa ada beberapa macam tipe kerusakan pada pengujian impak yang dapat dideteksi seperti: retak, delaminasi pada skin, debonding antara skin dan core, serta kerusakan di dalam core [7]. Luas kerusakan impak pada struktur sandwich dipengaruhi oleh material core dari tumpukan laminasi permukaan sandwich, ukuran, massa, kecepatan pendulum dan kemampuan dari komponen sandwich untuk menyerap beban kejut. Pada struktur sandwich dengan core, delaminasi dapat dideteksi pada daerah terimpak yang berada di antara skin dan core. Macam-macam kerusakan akibat beban impak ditunjukkan pada gambar 2 .

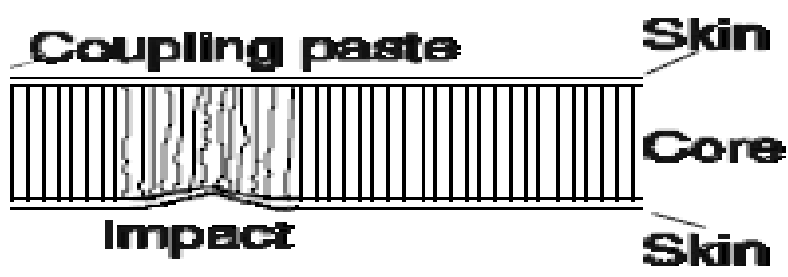

Gambar 2 Kerusakan pada struktur sandwich akibat beban impak [7] 


\section{METODOLOGI PENELITIAN}

\section{Bahan dan Alat Penelitian}

Bahan utama penelitian adalah serat rami (woven) dengan density $1.6 \mathrm{gr} / \mathrm{m}^{3}$, serat E-Glass (woven)dengan density $450 \mathrm{gr} / \mathrm{m}^{2}$, bahan core serbuk kayu jati dan mahoni pada mesh 30 dengan density $0.68 \mathrm{gr} / \mathrm{m}^{3}$ dan $0.62 \mathrm{gr} / \mathrm{m}^{3}$, unsaturated poliester type $157 \mathrm{BQTN}$, dan hardener MEKPO dengan kadar 1\%. Peralatan yang digunakan adalah Mesin uji impak Charpy, timbangan untuk menentukan fraksi volume serat foto makro, oven pengering, press mold.

\section{Pembuatan Spesimen Uji}

Spesimen uji komposit sandwich hibrid dibuat dengan metode press mold. Fraksi volume serat lamina komposit hibrid/ skin bagian ditentukan 30\%, yang dikontrol dengan ketebalan komposit sandwich hibrid saat pencetakan. Komposit sandwich hibrid tersusun dari dua skin komposit hibrid dengan core hibrid serbuk kayu jati dan mahoni di bagian tengahnya. Lamina komposit hibrid tersusun dari 2 lamina serat E-glass woven dan 1 lamina serat rami woven. Posisi serat E-glass ditempatkan pada sisi terluar yang menerima beban lebih berat. Serat rami yang digunakan terdiri dari serat tanpa perlakuan. Core hibrid serbuk kayu jati dan mahoni dibuat dengan metode press mold. Fraksi volume core divariasi 30\%, $40 \%$, dan 50\% ditunjukkan seperti pada gambar 3 .

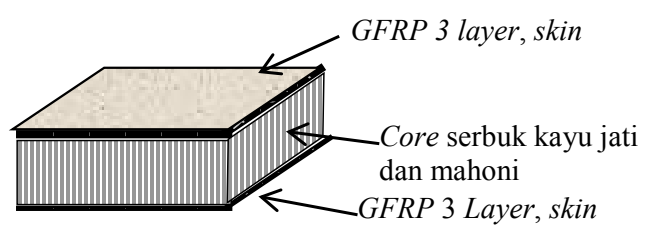

Gambar 3. Komposit sandwich hibrid [8]

Agar hasil penelitian lebih komprehensif, maka komponen penyusun komposit sandwich hibrid juga dilakukan uji impak. Pembuatan spesimen ini dilakukan tersendiri dengan mengacu standar ASTM D 5942 (untuk impak komposit sandwich).

\section{Metode Pengujian Spesimen Uji}

Berhubung aplikasi komposit sandwich hibrid adalah untuk panelling/kereta api, bis, maka pengujian yang penting dilakukan adalah uji impak. Pengujian impak dilakukan menurut standar ASTM D 5942. ditunjukkan pada gambar 4 dan 5 untuk Pemasangan spesimen uji impak (flat wise impact) dan spesimen uji impak charpy.

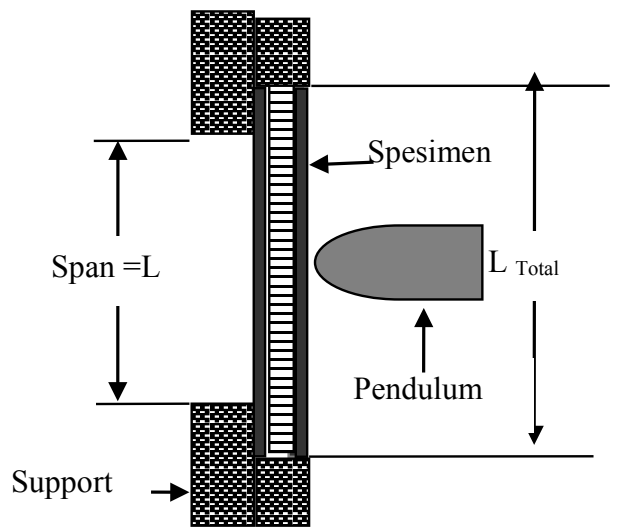

Gambar 4. Pemasangan spesimen uji impak ( Flat wise Impact ) 


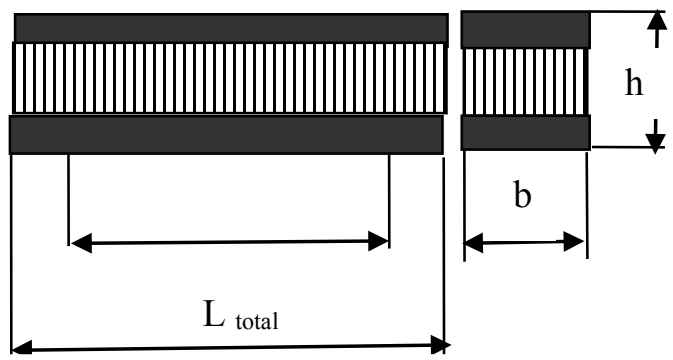

Gambar 5. Spesimen uji impak Charpy

\section{HASIL PENELITIAN DAN PEMBAHASAN Analisis Kekuatan Impak}

Tabel 1

Energi serap komposit sandwich hibrid

\begin{tabular}{cc}
$\begin{array}{c}\text { Fraksi Volume } \\
(\%)\end{array}$ & $\begin{array}{c}\text { Energi Serap } \\
\text { W(Joule) }\end{array}$ \\
\hline 30 & 7.81 \\
\hline 40 & 7.92 \\
\hline 50 & 8.12
\end{tabular}

Tabel 2

Kekuatan impak komposit sandwich hibrit

\begin{tabular}{cc}
$\begin{array}{c}\text { Fraksi Volume } \\
(\%)\end{array}$ & $\begin{array}{c}\text { Kekuatan Impak } \\
\mathrm{a}_{\mathrm{cu}}\left(\mathrm{J} / \mathrm{mm}^{2}\right)\end{array}$ \\
\hline 30 & 0.066 \\
40 & 0.067 \\
50 & 0.068 \\
\hline
\end{tabular}

Komposit sandwich hibrid yang diperkuat serat rami dan E-Glass tanpa perlakuan mampu menyerap energi yang lebih tinggi, seperti ditunjukkan pada tabel 1. Energe serap meningkat seiring dengan penambahan fraksi volume core, seperti ditunjukkan pada gambar 6. Dengan demikian, penambahan bagian inti struktur sandwich hibrid menunjukkan secara signifikan peningkatan kemampuan menyerap energi. Sifat material yang lebih lunak (core hibrid serbuk kayu jati dan mahoni) dan penambahan fraksi volume menyebabkan memiliki kemampuan menyerap energi yang lebih tinggi.

Bila ditinjau dari segi kekuatan impak seperti ditunjukkan pada gambar 7, kekuatan impak komposit sandwich hibrid meningkat secara signifikan seiring dengan penambahan ketebalan core. Kekuatan impak optimum pada fraksi volume core $50 \%$.

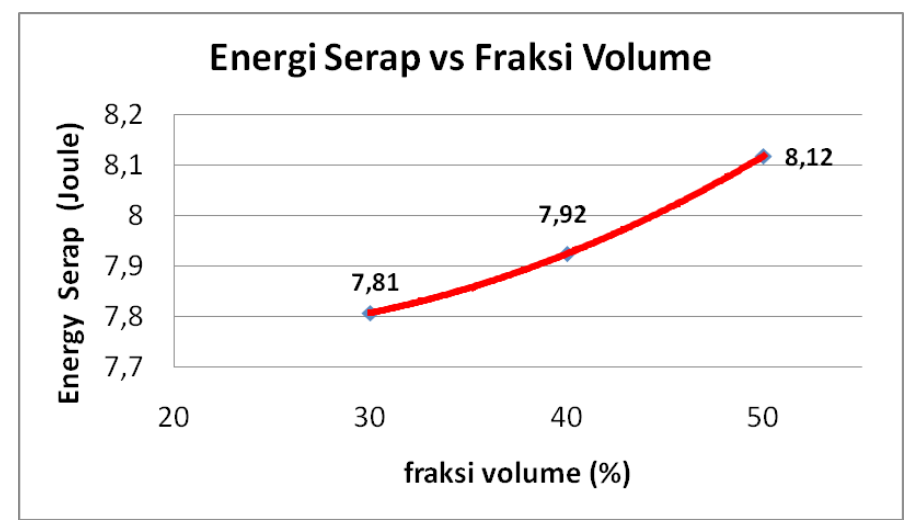

Gambar 6 Kurva energy serap komposit sandwich hibrid. 


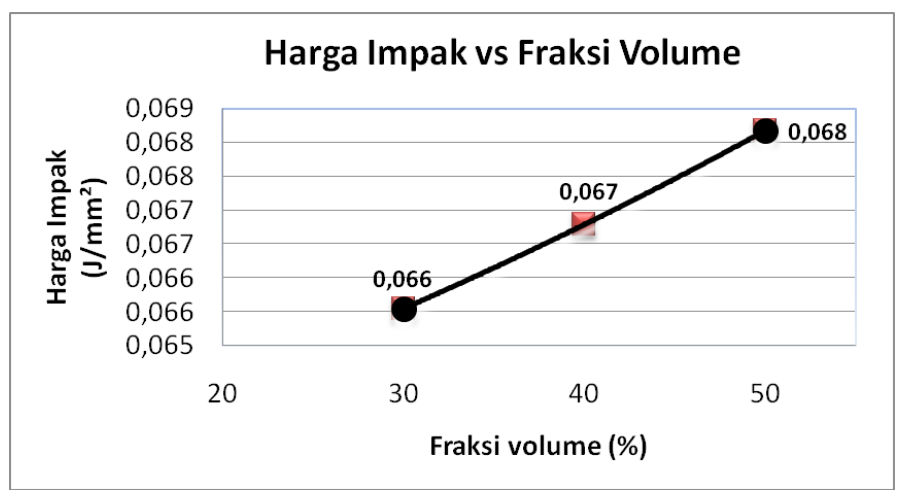

Gambar 7 Kurva kekuatan impak komposit sandwich hibrid.

Berdasarkan analisis yang dihitung dengan standar ASTM D 5942, komposit sandwich hibrid yang diperkuat serat rami dan E-Glass tanpa perlakuan, memiliki kekuatan impak yang lebih tinggi, seperti ditunjukkan pada gambar 7 . Hal yang sama menunjukkan bahwa energi serap yang paling optimum terjadi pada komposit sandwich hibrid dengan fraksi volume core $50 \%$.

\section{Analisis Pola Kegagalan}

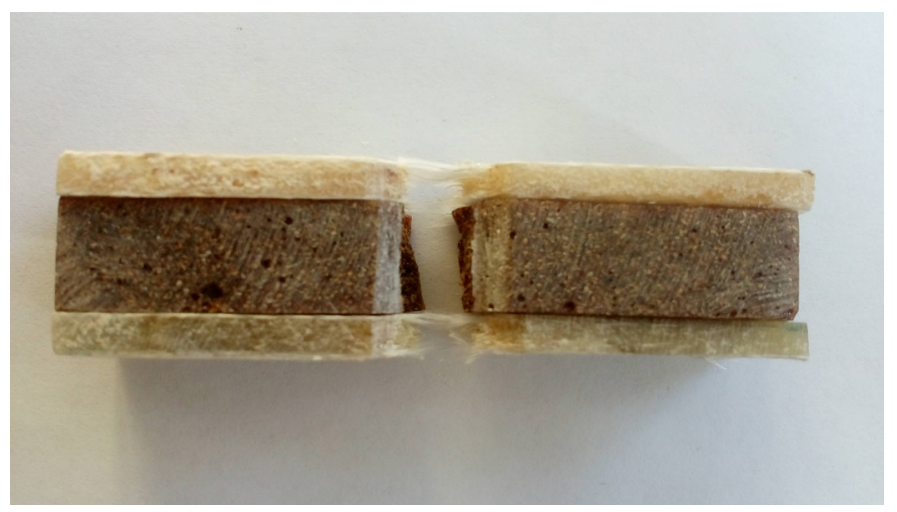

Gambar 8 Permukaan patah komposit sandwich hibrid pada $\mathrm{V}_{\mathrm{f}}=30 \%$

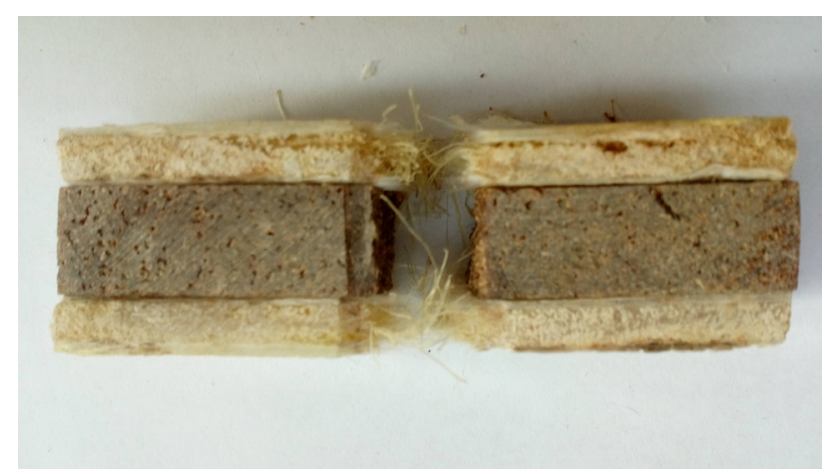

Gambar 9. Permukaan patah komposit sandwich hibrid pada $\mathrm{V}_{\mathrm{f}}=40 \%$ 


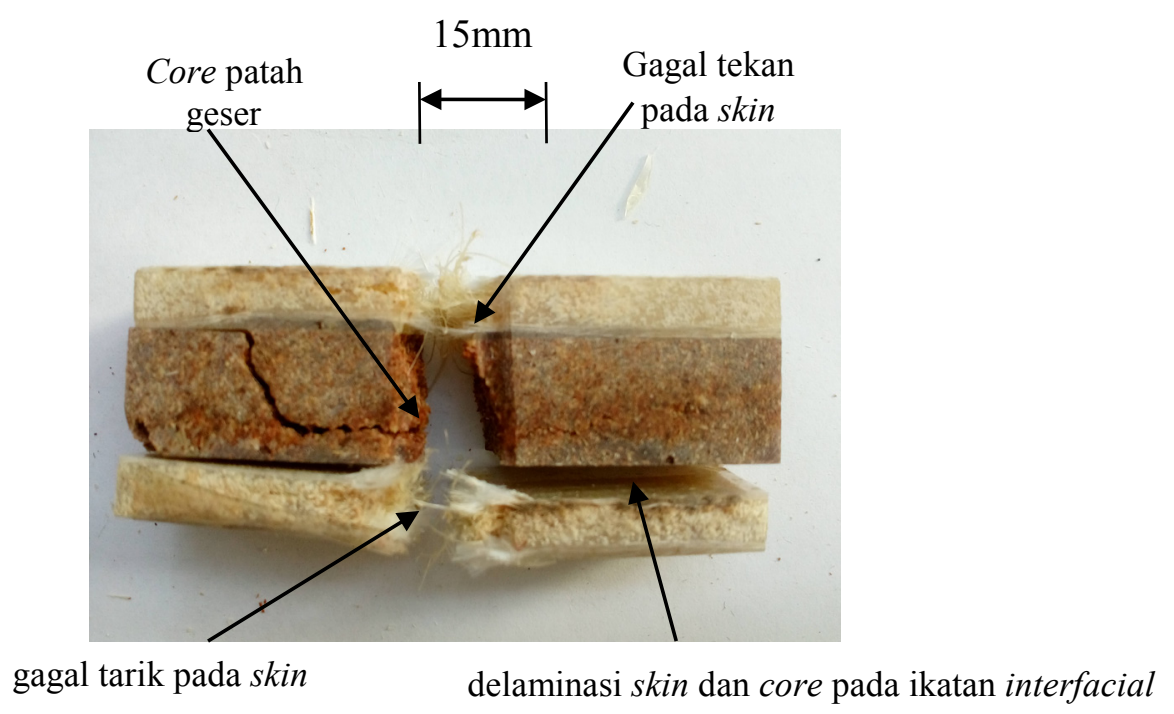

Gambar 10. Penampang patahan komposit sandwich hibrid pada $\mathrm{V}_{\mathrm{f}}=50 \%$

Kegagalan impak komposit sandwich hibrid ditunjukkan pada gambar 8, 9, dan 10 . Secara umum, pola kegagalan diawali dengan retakan pada komposit skin yang menderita tegangan tarik. Kemudian, beban impak tersebut didistribusikan pada core sehingga menyebabkan core mengalami kegagalan. Skin yang semula menderita beban tekan akhirnya mengalami kegagalan seiring dengan gagalnya core. Gambar 10 menunjukkan secara jelas adanya kegagalan tarik pada komposit skin bawah, gagal geser core dan kegagalan tekan pada skin atas. Mekanisme patahan terjadi karena kegagalan komposit sandwich hibrid akibat beban bending berawal dari skin komposit sisi belakang (bawah) dan dilanjutkan dengan kegagalan core, delaminasi skin dan core pada ikatan interfacial.

\section{KESIMPULAN}

Berdasarkan data hasil penelitian tersebut maka dapat disimpulkan sebagai berikut:

1. Penambahan fraksi volume core pada $30 \%$ hingga $50 \%$ pada komposit sandwich hybrid meningkatkan energi serap sebesar 7.81 hingga 8.12 Joule. Harga yang optimum pada fraksi volume core $50 \%$ sebesar 8.12 Joule.

2. Penambahan fraksi volume core pada $30 \%$ hingga $50 \%$ pada komposit sandwich hybrid meningkatkan kekuatan impak sebesar 0.066 menjadi 0.068 Joule $/ \mathrm{mm}^{2}$. Harga yang optimum pada fraksi volume core $50 \%$ sebesar $0.068 \mathrm{Joule} / \mathrm{mm}^{2}$.

3. Tahapan pola kegagalan komposit sandwich hibrid adalah kegagalan tarik skin komposit sisi bawah, kegagalan geser core, delaminasi skin komposit sisi atas dengan core, kegagalan skin komposit sisi atas.

\section{DAFTAR PUSTAKA}

[1] Hariyanto, A.,. 2006. Studi Perlakuan Alkali dan Tebal Core Terhadap Sifat Bending dan Impak Komposit Hybrid Sandwich Serat Kenaf dan Gelas Bermatrik Polyester dengan Core Kayu Sengon Laut, Tesis. Yogyakarta: Universitas Gajah Mada.

[2] Wahyanto, B, Diharjo, K, 2004, Karakterisasi Uji Bending Dan Impak Komposit Sandwich GRFP dengan Core Kayu Sengon Laut, Skripsi, UNS, Surakarta. 
[3] Febrianto, B, Diharjo, K, 2004, Kekuatan Bending dan Impak Komposit Hibrid Sandwich Kombinasi Serat Karung Goni dan Serat Gelas Polyester dengan Core Kayu Sengon Laut, Skripsi, UNS, Surakarta.

[4] Gibson, O. F., 1994. Principle of Composite Materials Mechanics, McGraw-Hill Inc., New York, USA.

[5] Shackelford, 1992. Introduction to Materials Science for Engineer, Third Edition, MacMillan Publishing Company, New York, USA.

[6] Annual Book of Standards, Section 8, D 5942-96, Standard Test Methods forDetermining Charpy Impact Strength of Plastics, ASTM, 1996.

[7] Hillger, 1998, Inspection of CFRP and GFRP Sandwich Components, Wilhelm Raabe Weg 13, D-3 8110 Braunschweig.

[8] Allen, H.G., 1969, Analisis and design of structural sandwich Panels, Pergamon press.

[9] Annual Book of Standards, Section 8, D 790-02, "Standard Test Methods for Flexural Properties of Unreinforced and Reinforced Plastics and Electrical Insulating Materials1", ASTM, 2002. 